\title{
Potentialities planning of sustainable ecotourism in the Kingdom of Saudi Arabia
}

\author{
A. O. Al-Sulbi \\ Department of Landscape Architecture, College of Architecture and \\ Planning, The University of Dammam, Kingdom of Saudi Arabia
}

\begin{abstract}
The Kingdom of Saudi Arabia (KSA) covers an area of more than 2.24 million $\mathrm{km}^{2}$, and overlooks coasts for more than 2,500 linear kilometres along the Red Sea and the Arabian Gulf. Its mainland is subdivided into thirteen regions which vary in their geomorphological and socio-cultural features. Such a spatial extent represents varieties of natural ecosystems; the most vulnerable and important ones were exemplified in sixteen protected areas which cover about $4.5 \%$ of the total area of the country. The diversification of natural habitats and ecosystems extends from deep seas through coastal plains to plateaus and harsh deserts.

The strategic movement toward promotion of the tourism industry in all regions of the KSA began in 2002 and has attracted huge investments in this newly growing sector as well as a change in tourists' attitudes. Most of the investments seek short-time profit, thus environmental issues and regional sociocultural differences are less considered in planning of most of the touristic projects.
\end{abstract}

Planning of ecotourism potentialities in the KSA requires holistic integration of both biocentic (nature-centred) and anthropocentric (human-centred) perspectives to maintain sustainable ecotourism at the national level, which is the function of environment, economy and equity (or justice).

Therefore, the aim of this paper is to promote sustainable ecotourism in the KSA through exploration of major natural potentialities and their opportunities for different types of ecotourism. It also tries to draw several planning and management guidelines in order to ensure acceptable environmental qualities and the sustainable use of the resources within their natural ecosystems.

Keywords: Saudi Arabia, sustainable ecotourism, natural ecosystems, protected areas, cultural values, potentialities planning. 


\section{Introduction}

It is thought that several factors including the development of mass media, accommodation and transportation facilities, increased disposable income and time, and improved access have enabled more people to enjoy leisure travel in new and more varied destinations (Fennell and Butler [1]).

Tourism industry is the largest fast growing economic sector; and the ecotourism represents the fastest growing part of this market in relevant to advances in transportation and information technologies. Based on the World Tourism Organisation (WTO) statistics in 2007, 50 countries constituted the top preferred destinations for about 903 million tourists. The KSA received about 11.5 million of them (UNWTO [2]).

Since the KSA is the birthplace of Islam, it has a special position and led an influential role in the Muslim world. The KSA is the home of the Two Holy Mosques, where it was and continues to attract millions of Muslim pilgrims from around the world. Muslims (who are the majority of tourists) are attracted to the KSA to perform pilgrimage and visit the holy places in and around the two cities of Makkah Al-Mukaramh and Al-Madinah Al-Munawarh in a form of religious tourism. However, the spatial extent of the KSA exhibits natural heritage and cultural patrimony; and constitute a toast to the concerns of visitors. The facilities have the latest in the area of travel within the KSA to provide such sites for each of the pilgrims and visitors. These provide great opportunities for various ecotourism products representing the variation in environmental setting and socio-cultural values of each region. In addition, the current developed infrastructure in transportation and public utilities sector provide good bases to serve an appropriate planning and development of sustainable tourism industry.

In its way to promote tourism as one of the major economic sector to minimise dependence on oil, the KSA has promulgated the Saudi Commission for Tourism and Antiques (SCTA) in April 2000 to organise, develop and promote tourism products and encourage external as well as internal tourists to visit areas of distinctive attractions within the country (STCA [3]).

To achieve its goal, the SCTA has promoted Tourism Development Strategies for all regions of the country through its initiated regional committees, and

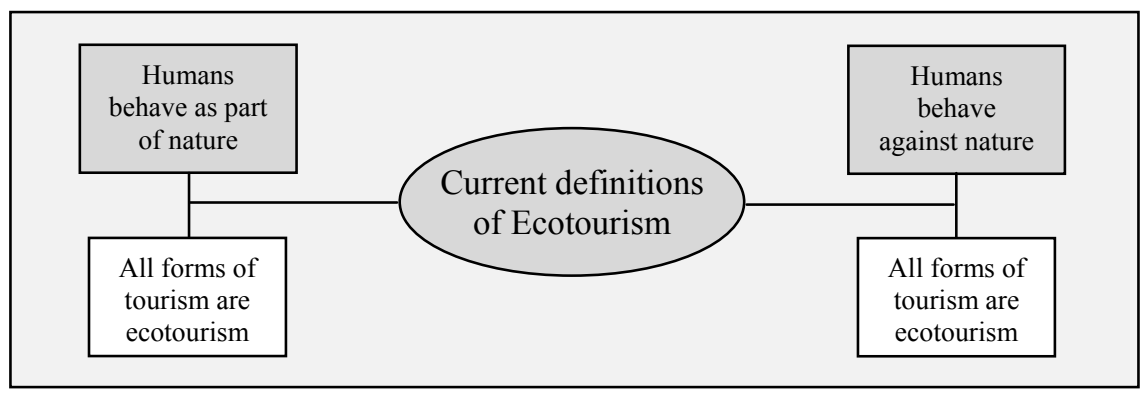

Figure 1: Definition of ecotourism in relation to human influences. 
carried out a national wide survey resulted in recording and assessment of more than 12,000 sites of natural and socio-cultural heritage (figure 1).

\section{Ecotourism and sustainable tourism}

Ecotourism appeared in literature for the first time in 1983 by a Mexican environmentalist Hector Ceballos, to describe nature-based travel to relatively undisturbed areas, with emphasis on education.

Miller and Kaae [4] have argued that application of the concept of ecotourism is viewed as part of a continuum paradigm that is bounded by polar extremes of relatedness to nature. At one pole, all tourism (including ecotourism) has considered the negative impacts on the natural world because humans are separated in their activities from nature. At the other extreme, organisms' behaviour (including human) are part of the natural process and, as a result, they are unable to behave unnaturally (figure 1). Consequently, all types of tourism can be considered as ecotourism because there is no difference between ecotourism and other forms of tourism (Miller and Kaae [4]).

In reality, types and forms of ecotourism might be easily located between the two polar extremes and can be classified based on their tendency to be consistent with their degree of impact on the natural environment (Orams [5]). Therefore, ecotourism as classified by Orams [6] is located between the two polar extremes and might be either sustainable or not, according to the severity of its impacts on the natural environment (figure 2).

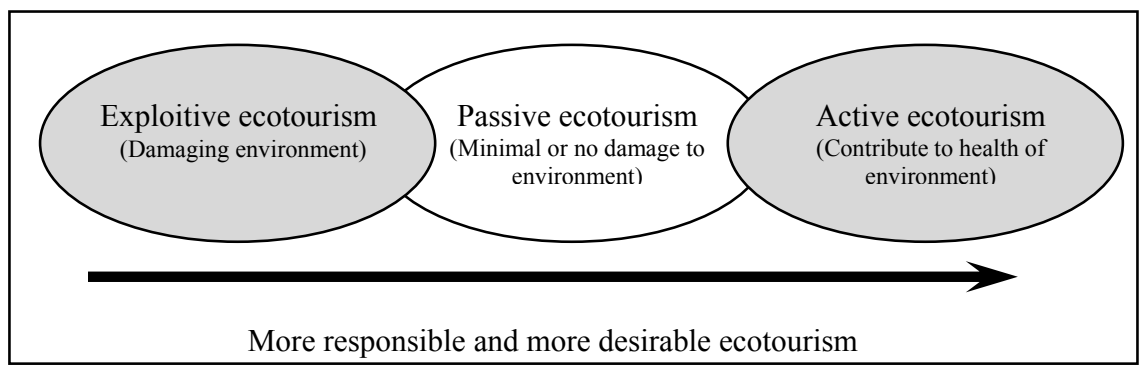

Figure 2: $\quad$ Continuum of ecotourism types (after Orams [6]).

At one polar extreme, ecotourism tends to preserve the integrity, stability and beauty of the environment and its communities. In this case, ecotourism actively contributes to the improvement of the environment as a whole, and is considered more positive and responsible. At the other polar extreme, natural resources are irresponsibly exploited that definitely cause severe damage to the host environment. Between these two extremes, other types of ecotourism - that may be viewed as more neutral and passive - take place.

Ecotourism has become a debatable subject since the 1980 s to clarify its definition and types. It is generally a form of tourism that fosters learning experiences and appreciation of the natural environment and its resources within 
the socio-cultural context; and applies more emphasis to sustainability of natural and socio-cultural heritage (Weaver [7]). Thus sustainable tourism is applicable to all forms of tourism in all types of destinations, seeks to apply sustainability principles referring to the environmental, economic and socio-cultural aspects of tourism development. Thus it emphasises optimal use of environmental resources, maintaining essential ecological processes, helping to conserve natural heritage and biodiversity, and respecting the socio-cultural authenticity of host communities (WTO [8]). Therefore, ecotourism is considered as a subset of sustainable tourism when it emphasises the concepts mentioned above (Weaver [7]).

\section{Methods and tools}

This paper is developed based on the exploration of literature dealing with tourism potentialities of the KSA regions and the personal experience of the author. A general survey was undertaken to identify the potentialities and characteristics of each region. The vast area of the KSA presents different natural features, geomorphologic characteristics and social variations which require careful planning to maintain sustainability of society as well as the environment.

\subsection{Data collection}

By exploring the reports discussing a Regional Tourism Development Strategy, in addition to personal visits to some of the regions to help identify natural and socio-cultural potentialities for ecotourism promotion; this paper is not the place to list and explain them. As a result of this, several forms and types of ecotourism can be identified and promoted in certain regions of the country.

The differences of natural and socio-cultural heritage of different regions require special attention in planning these potentialities.

\section{Background}

The KSA was unified and known by this name for the first time on $21^{\text {st }}$ September 1932. It composes most of the Arabian Peninsula's area (figure 3), which is thought to have been inhabited 40,000 years ago (MOCI [9]). Since its unification and stability, the KSA has witnessed massive and rapid urbanisation and development which has transformed it into a modernised country.

The KSA overlooks the Red Sea on the west for approximately $1,850 \mathrm{~km}$. Its other neighbouring states are: Kuwait, Iraq and Jordan from the north; Yemen and Oman from the South; and Oman, the United Arab Emirates and Qatar from the east in addition to about $700 \mathrm{~km}$ on the Arabian Gulf.

The KSA has a subtropical climate, and it occasionally might be subjected to disturbed tropical monsoon weather which brings rain to the southern parts in summer where in winter the mid-latitude low pressure system penetrates the north of the country giving rise to most rain, or snow, in the country's northern 


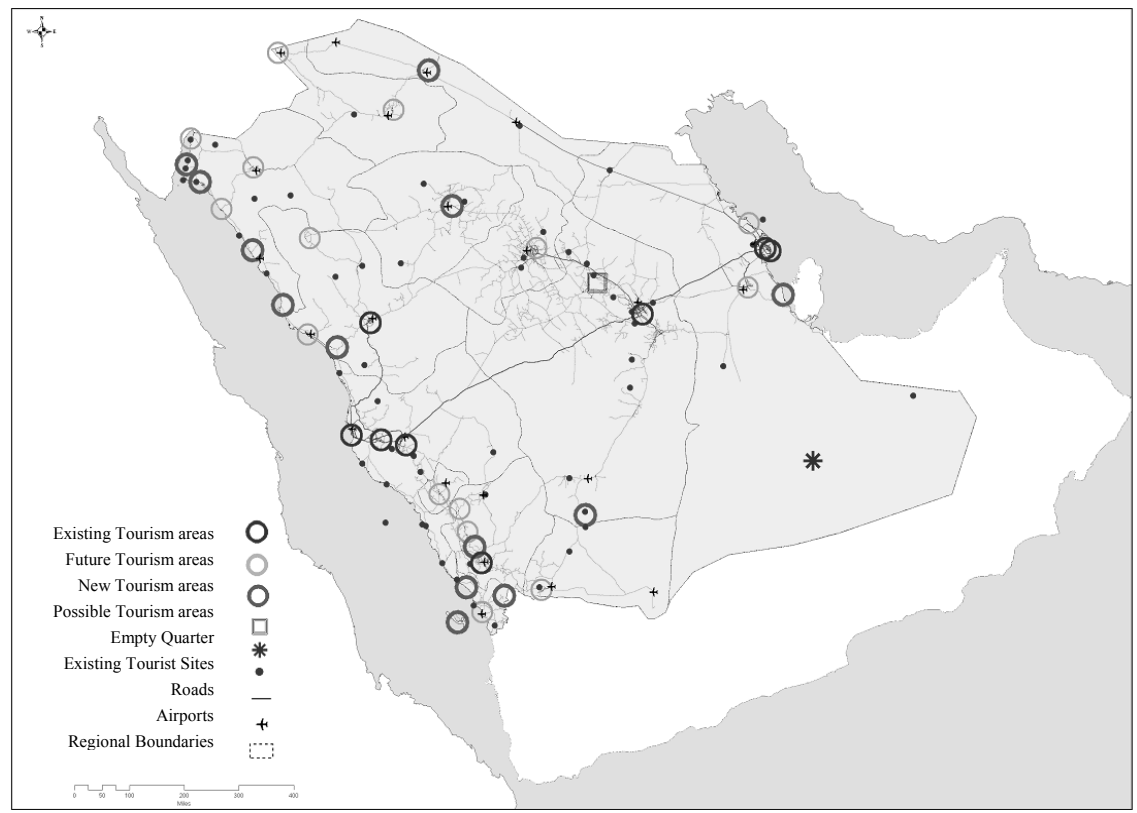

Figure 3: $\quad$ Existing and potential tourism areas cover all regions of the KSA.

part. Orographic rainfall due to high altitudes and proximity to the Red Sea augments precipitation along the south western escarpment. On-shore sea breezes force the moist air from the Red Sea during the daytime to ascend, giving rise to afternoon showers and thunderstorms. Annual precipitation varies from less than $50 \mathrm{~mm}$ in the south eastern parts to more than $500 \mathrm{~mm}$ in the mountains to the south of At-Taif city (Child and Grainger [10]).

Temperatures are subject to considerable diurnal and seasonal fluctuations. Winters are cool to warm with uncommon frost at nights and occasional snowfalls in the north and at high altitudes. Summers tend to be very hot with temperatures above $40^{\circ} \mathrm{C}$ and sometimes exceeding $50^{\circ} \mathrm{C}$. Humidity is generally low during summers, ranging between $15 \%$ and $65 \%$ with almost dry air in the interior; and exceeding $70 \%$ along the coasts during winter nights (Child and Grainger [10]).

\subsection{Administrative governance}

The KSA is located at the crossroads connecting the continents of Asia, Africa and Europe. It occupies 2.24 million $\mathrm{km}^{2}$, approximately four-fifths of the Arabian Peninsula's area (MOCI [9]; Child and Grainger [10]), and its population exceeds 22.7 million inhabitants where approximately one-third of them concentrate along the coastal areas (MOEP [11], MOCI [9], Burke et al [12]). From the administrative point of view, the KSA consists of thirteen regions (figure 3 ) each headed by a governor or Emir. Each region is divided into 
a number of governorates followed by a number of administrative centres controlling the local affairs of surrounding towns and villages. The Emir lives in the capital of the region, and acts as chief administrator of the whole region, oversees all its affairs and controls all governmental departments and public organisations. Through his wide powers, the Emir is responsible for the overall development of the region as he chairs the Provincial Council which consists of representatives of ministries in the region, and includes at least ten citizens.

Decision making in the KSA is a centralised system where all suggested plans by governmental bodies (including ministries, higher committees and commissions) to be implemented at a national level travel bottom-up and topdown for discussion in the Council of Ministers (CM); and usually the CM refers to the King for approval or submits the plans to the Consultative Council (CC) for study and final check before approval (Al-Buthie and Eben Saleh [13]).

\subsection{Geophysical setting of the KSA}

The KSA occupies most of the two huge crustal plates: the Arabian shield and the Arabian Shelf. The Arabian shield is an ancient land mass in the western part of the Arabian Peninsula composed of igneous and metamorphic rocks of the Precambrian age. The Arabian shelf lies to the east of the shield and is composed of sedimentary deposits of limestone, sandstone and shale resulting from inundation by a series of shallow seas. The sedimentary deposits gently slope eastwards and range, in age, from the Cambrian to the Pliocene. Unconsolidated Quaternary-aged sand and gravel deposits cover most of the KSA eastern parts while Aeolian sands spread along large parts of the north, east and south of the country (Chapman [14]).

From the topographical point of view, the KSA may be divided into a number of distinctive regions, each are of special features; and within these regions there are sub-regional divisions suggested by Child and Grainger [10] in their physiographic map of the KSA (figure 4). Among the six major physiographic regions, coastal plains and both the Red Sea and the Arabian Gulf are important for this study. Territorial waters of both seas and their coastal plains make up the whole or part of the KSA coastal zones.

Coastal plains are located along the two coasts of the KSA and vary in their characteristics. The Tihamah coastal plain (1a in figure 4) forms a narrow transitional zone between the Red Sea and the adjacent foothill to the east. It is very narrow in the north virtually disappearing above latitude $27^{\circ} \mathrm{N}$ but widens irregularly towards the south reaching a maximum width of $40 \mathrm{~km}$ near Jizan. A number of seasonally flooding valleys cross the Tihamah coastal plain in areas marked by Aeolian sands and gravels washed down from coastal mountains.

The Arabian Gulf coastal plain ( $1 \mathrm{~b}$ in figure 4 ) is wide gradually slopes eastward and by extensive salt flats (sabkhah) where, in some places, the wateredge may shift several kilometres when large sabkhah are inundated. These salt flats facilitate the movement of rolling sandy sheets toward the coast.

The Arabian Gulf is a shallow sea sloping eastward at a rate of 3.5\%; the deepest point is about $100 \mathrm{~m}$ locates at its entrance in the Strait of Hormuz where 


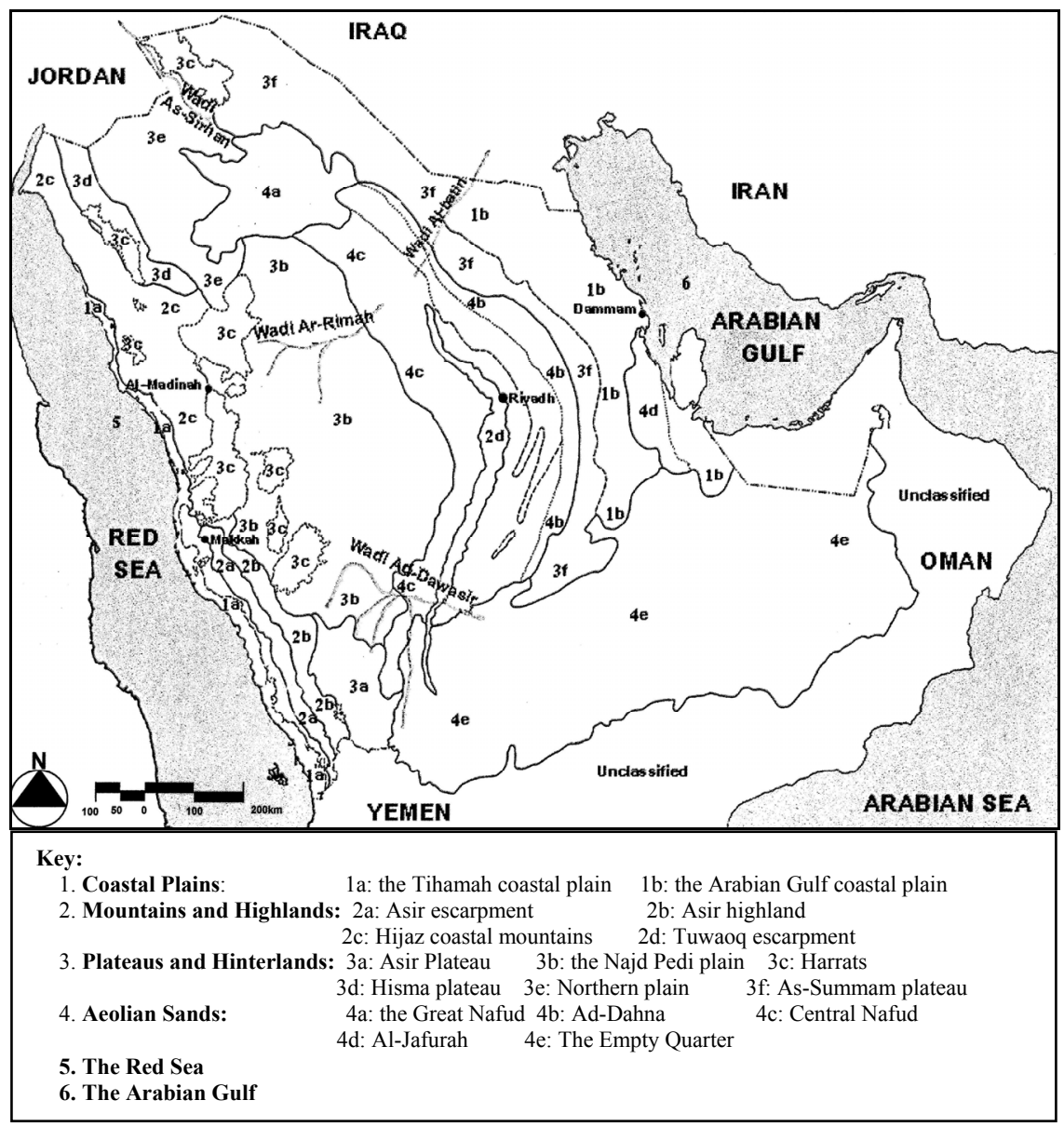

Figure 4: $\quad$ Boundaries and administrative regions of the KSA.

its average depth is $31 \mathrm{~m}$ (Sheppard et al. [15]; Al-Mansi [16]). The Arabian Gulf is characterised by its combination of bays and peninsulas series which are known locally as Dawhat such as Dawhat Ad-Deffi and Dawhat Al-Musalamyah north of the Jubail Industrial City (JIC) and Dawhat Zalum south of Khubar city and its coastal areas are extensive sabkhah (Miller and Kaae [5]). Furthermore, along the wide coastal plain of the Arabian Gulf extensive areas originally covered with rounded water-borne gravel buried under a thin layer of sand sheets in some places.

The Red Sea, on the other hand, is a longitudinal and narrow water body, about 2,000 km long and an average width of $280 \mathrm{~km}$. Although, its average depth is about $500 \mathrm{~m}$ it reaches $2,500 \mathrm{~m}$ in some areas (Al-Mansi [16]). The eastern coast of the Red Sea faces the Sarawat Mountainous Range, from where a number of big valleys flow down to the sea, where mangrove forests are flourishing on muddy flats and beaches. 


\section{Discussion}

The huge area of the KSA and its spatial extent to contain varieties of physiographic, socio-cultural and natural features encourage different forms of tourism that need to be planned and managed to achieve both natural and socioeconomic sustainability. To ensure that, ecotourism need to be promoted as a tool for sustainable development which requires emphasising local values and customs, and social differences at local and regional levels.

The Saudi community is conservative and hospitable, controlled by special values and social customs which are strongly believed in among tribal communities in remote areas or isolated areas. Thus, introduction of ecotourism into such communities will bring different cultures that might be unacceptable which require specific training programmes and gradual involvement of local people into ecotourism programmes. This, if properly implemented, will improve their life style and foster their sense toward conservation of natural capital of their local environment.

Planning these potentialities must stress the following points:

- Planning and management of tourism development (in general) should emphasise conservation of natural and socio-cultural heritage at national level, and avoid any practices that may cause damages and/or imperfections to the environment, economy and society of the destination areas.

- A holistic vision is must in planning for sustainable ecotourism. By which natural and socio-cultural heritage is appreciated and all regions are treated according to their potentialities for ecotourism where development should be balanced to cover all regions of the country. This holistic approach should also balance the natural opportunities and characteristics of individual sites for the benefits of place as well as the local society, and any development should not harm environment and community or influence their integrity and stability. Also holistic approach to ecotourism planning should develop a balance between biocentic (nature-centred) and anthropocentric (human-centred) perspectives and integrate them to maintain sustainability at national level.

- Regional Tourism Development Strategies need to identify areas (cities, towns and villages) within the region that are going to host specific tourism form in order to facilitate monitoring and measure indicators of sustainability.

- Planning for sustainable ecotourism in the KSA should emphasise the concept of locally-oriented benefits to destination areas and, at the same time, socio-cultural sustainability should be warranted in order to foster the levels of community support for ecotourism that is necessary to adequately protect local natural heritage base on which the ecotourism sector relies.

\section{Conclusion}

The KSA represents huge potentialities for different forms of ecotourism varies from diving to deep sea habitats in the Red Sea to desert exploration of various 
physiographic features crossing sand dune seas to shallow water habitats of the Arabian Gulf. Within these variations of natural heritage, similar varieties of socio-cultural attractions including historical and indigenous architectural monuments as well local customs and traditions can be seen differently in different regions.

Promotion of such potentially require careful planning to conserve social values and maintain environmental sustainability which the main capital for ecotourism. This will necessitate comprehensive coordination and integration between private and public sectors in order to plan and manage ecotourism development toward the achievement of sustainability principles and beneficiary of both natural environment and local community.

\section{References}

[1] Fennell, D. and Butler R. (2003) A human ecological approach to tourism interactions, International Journal of Tourism Resources, 5, pp. 197-210

[2] UNWTO, 2009, UNWTO World Tourism Barometer, volume 6, no. 2, 2008, http://www.tourismroi.com/Content_Attachments/27670/File_ 633513750035785076.pdf, accessed 21 December 2009.

[3] SCTA, 2010, Saudi Commission for Tourism and Antiques: promulgation and goal, http://www.scta.gov.sa/Aboutus/Pages/Establishment_and goals.aspx, accessed 12 January 2010.

[4] Miller Marc L. and Berit C. Kaae (1993) Coastal and Marine Ecotourism: A Formula for Sustainable Development? Trends, vol. 30, no. 2. pp. 35-41. U.S. Department of the Interior, National Park Service.

[5] Orams, M., 2001, Types of ecotourism, in Weaver, D. (editor), The Encyclopaedia of Ecotourism, CBA International, London, UK, pp. 23-36

[6] Orams, M. (1995) Toward more desirable form of ecotourism, Tourism Management, vol. 16, no. 1, pp. 3-8

[7] Weaver, D. (2001) Ecotourism, John Wiley and Sons, Sydney

[8] WTO, (2010) Sustainable development of tourism: conceptual definition, http://www.world-tourism.org/sustainable/top/concepts.htm, accessed 28 February 2010.

[9] MOCI, (2003) Ministry of Culture and Information, This Is Our Country, Saudi Desert House for Publishing and Distribution, Riyadh.

[10] Child, G. and Grainger, J. (1990) A System Plan for Protected Areas for Wildlife Conservation and Sustainable Rural Development in Saudi Arabia, National Commission for Wildlife Conservation and Development (NCWCD), Riyadh.

[11] MOEP: Ministry of Economy and Planning (2004a) Initial results of 2004 population census (Arabic), Central Department of Statistics, www.planning.gov.sa/docs/, accessed March 2, 2010.

[12] Burke, L., Kura Y., Kassem K., Revenga C., Spalding M. and McAllister D. (2001) Pilot analysis of global ecosystems: coastal ecosystems, http://marine.wri.org, accessed December 20, 2009. 
[13] Al-Buthie, I. and Eben Saleh, M. (2002) Urban and industrial development planning as an approach for Saudi Arabia: the case study of Jubail and Yanbu, Habitat International, 26, 1-20.

[14] Chapman, R. (1978) General information on the Arabian Peninsula: 1.1 Geology, in Al-Sayari, S. and Zolt, J. (editors) the Quaternary Period in Saudi Arabia, Springer Verlag, New York.

[15] Sheppard, C., Price, A. and Roberts, C. (1992) Marine Ecology of the Arabian Region: Patterns and Processes in Extreme Tropical Environments, Academic Press, Harcourt Brace Jovanovich Publishers, London.

[16] Al-Mansi, A. (1999) Ecosystems of the Red Sea and the Arabian Gulf, (Arabic), Al-Humadhi Press, Riyadh. 